\title{
Comparing the early function and complications between fluoroscopic guidance and blindly insertion of permanent hemodialysis catheter
}

\author{
Nasser Malekpour Alamdari ${ }^{1 *}$, Samad Shams Vahdati², Barmak Gholizadeh ${ }^{1}$, Shima Nayebian ${ }^{1}$ \\ 'Department of General Surgery, Shahid Beheshti University of Medical Sciences, Medical School, Tehran, Iran \\ ${ }^{2}$ Department of Emergency Medicine, Tabriz University of Medical Sciences, Tabriz, Iran
}

\begin{abstract}
Received: 18 April 2018
Accepted: 29 June 2018

Published online: 9 July 2018

*Corresponding author: Nasser

Malekpour, Assistant Professor of

Vascular Surgery, Shahid Behesht

University of Medical Sciences,

Tehran, Iran.

Tel: 09128246152

Email: nassermalekpour@gmail.com

Competing interests: None.

Funding information: None.

Citation: Malekpour Alamdari

$\mathrm{N}$, Shams Vahdati S, Gholizadeh

$\mathrm{B}$, Nayebian S. Comparing the

early function and complications

between fluoroscopic guidance

and blindly insertion of permanent

hemodialysis catheter. Journal of

Emergency Practice and Trauma

2019; 5(1): 19-22. doi: 10.15171/

jept.2018.10
\end{abstract}

\begin{abstract}
Objective: Chronic kidney disease (CKD) is a complicated kidney defect causing permanent failure in renal function in progressive stages. Hemodialysis is the most accepted treatment to maintain body's fluid/electrolyte homeostasis at the terminal stages of the disease. Permanent hemodialysis catheter (permicath) may be inserted blindly or by fluoroscopic guidance. This study aimed to compare the early function and complications between fluoroscopic guidance and blindly insertion of permanent hemodialysis catheter.

Methods: This prospective randomized clinical trial was undertaken in the emergency department of Modarres hospital in Tehran, Iran during 2014 and 2015. Patients who needed catheter due to renal failure entered the study. Patients who needed emergency dialysis and those who could not wait for permicath were excluded. Patients were randomly assigned into 2 groups, under fluoroscopic guidance and blindly catheter insertion. Data were collected using a questionnaire and a checklist related to function (after 24 hours and 1 month), a need to exchange the catheter and the early adverse effects such as pneumothorax, hemothorax, and vascular injury.

Results: A total of 101 patients were enrolled in this trial. Early dysfunction (blind group= 5 ), a need for catheter exchange (blind group $=2$ ), pneumothorax (blind group $=2$ ), vascular injury (blind group $=1$ ) were recorded but the difference between the two groups was not statistically significant $(P>0.05)$.

Conclusion: We did not observe a significant difference between the placement of permicath by fluoroscopic or blind method. However, more studies with larger groups are recommended.

Keywords: Permanent hemodialysis catheter, Fluoroscopic guidance, Blindly insertion
\end{abstract}

\section{Introduction}

Chronic kidney disease (CKD) is a progressive kidney dysfunction due to irreversible decreased renal function impairment. Dialysis and kidney transplantation are available options to prevent life-threatening uremia $(1,2)$. The worldwide prevalence of chronic renal failure is 242 per million subjects and annually eight percent are added to this rate (3). The reported prevalence and incidence rates of CKD in Iran are 357 and 57 per million, respectively (4). The most common used management method is hemodialysis with a worldwide increasing rate $(5,6)$. Regarding low accessible kidney donors, majority of patients should continue the hemodialysis $(6,7)$.

Permanent hemodialysis catheter, due to larger diameter and flow, is an applicable method for vascular access in CKD patients (8). These catheters are concealed without restriction in physical activity and additional care by patients is not required (9). However, some adverse effects may be seen such as bleeding, hemothorax, pneumothorax, tamponade, and arrhythmia. Late side effects such as venous thrombosis, functional impairment, and infection may be seen $(10,11)$.

Permicath is used in the maturation period of AVF to perform hemodialysis because non-tunneled central catheters may not be used up to four weeks due to the side effects such as infection and thrombosis $(12,13)$. Hemodialysis is required due to lack of sufficient donors for kidney transplantation (14). Better hemodialysis methods with higher quality would result in increased quality of life. Also, good vascular access would increase the efficiency of treatment, quality of life, and the treatment course. In addition, it decreases the hospital 
stay and mortality rate (15-17).

\section{Methods}

In this prospective randomized clinical trial, 101 patients who visited the emergency department of Modarres hospital in Tehran during 2014 and 2015 and needed catheter because of renal failure were invited in the study as they met the inclusion criteria for permicath. Patients who needed emergency dialysis and could not wait for permicath were excluded. The inclusion criteria encompassed dialysis need for more than one month. Previous central catheterization was considered as the exclusion criteria. Early function and complications of tunneled dialysis catheterization by fluoroscopic guidance were compared with blind method. The procedures were done by one vascular surgeon.

Subjects were randomized in blind and fluoroscopic guidance groups.

In the blind group after usual preparation, the patient was positioned in Trendelenburg with mild extension and rotation of the neck away from the side of internal jugular insertion.

In the blind approach after local anesthesia, the puncture needle was inserted following ultrasound, between the medial and lateral heads of the sternocleidomastoid muscle and lateral to the carotid artery with 45 degrees directed to ipsilatral nipple. In the modified Seldinger technique after blood flushback, quidewire advanced through the needle and needle was removed. A small incision (\#11 blade) was made at the guidewire skin enterance and extended to about $5 \mathrm{~mm}$. The exit site marked on the chest wall was also incised about $5 \mathrm{~mm}$. The subcutaneous tunneler was inserted into the chest incision and passed above the clavicle into the neck wound and catheter was pulled into the neck wound. The tract into the internal jugular vein was dilated over the guidewire, and the introducer sheath was inserted. Through this sheath catheter passed into centeral vein approximate supra vena caval and right atrium junction. Two lines were aspirated for more confidence and then were filled with serum-heparin.

In the other group, fluoroscopic guide was used to see proper situation of wire and check the exact position and kinking of the catheter.

The early dysfunction and complications were seen during catheterization up to 24 hours after it and included the need to exchange the catheter because of malfunction, hemothorax, pneumothorax, vascular injury, and thoracotomy. Hemothorax and pneumothorax were assessed by chest radiography. One month later, all patients were again assessed for catheter malfunction and thrombosis of catheter

SPSS software version 22 was used to perform the statistical analyses. Chi-square, student t test, and Fisher exact test were used and were considered statistically significant at $P$ values less than 0.05 .

\section{Results}

Totally, 101 patients were included in our trial in which in 51 patients permicath catheter was inserted blindly and in 50 patients it was inserted under fluoroscopic guidance. We did not observe a statistically significant difference regarding age between the two groups $(P=0.25)$ (Table $1)$. Diabetes and hypertension were the most common underling diseases with $20.6 \%$ and $19.8 \%$ incidences respectively. Diabetes plus hypertension have been seen in $19.6 \%$ patients. $6.5 \%$ of patients had no underlying disease (Table 2). Function status at the first 24 hours was $98.1 \%$ and $100 \%$ in blind group and fluoroscopic group respectively $(P=0.98)$. Function status in the first month in the blind group was $90.2 \%$ and it was $98 \%$ in fluoroscopic group $(P=0.31)$. Function was better in fluoroscopic guidance group without a statistically significant difference $(P>0.05)$. The need to exchange was more in blind group but we did not observe a significant difference $(P>0.05)$. Complication rate was $5.8 \%$ in the blind group but without any complication rate in fluoroscopic guidance group. Despite this difference, there was not a statistically significant difference between the two groups (Table 3).

\section{Discussion}

End-stage renal disease (ESRD) is the final stage of kidney disease requiring dialysis to prevent uremia. Nowadays the

Table 2. Frequency of disease

\begin{tabular}{lcc}
\hline Disease & No. & $\%$ \\
\hline Diabetes mellitus & 22 & 20.6 \\
Hypertension & 20 & 19.8 \\
Diabetes mellitus plus hypertension & 21 & 19.6 \\
\hline Hypertension plus others & 8 & 7.5 \\
\hline Diabetes mellitus plus others & 1 & 0.9 \\
\hline Diabetes mellitus plus hypertension plus others & 4 & 7.3 \\
Others & 18 & 17.8 \\
\hline Without Disease & 7 & 6.5 \\
Total & 101 & 100 \\
\hline
\end{tabular}

Table 1. Comparison of age between the two groups

\begin{tabular}{lccccc}
\hline & \multicolumn{4}{l}{ Age } \\
\cline { 2 - 5 } & Mean & SD & Minimum & Maximum & P value \\
\hline Blind $(n=51)$ & 58.7 & 2.2 & 23 & 92 \\
Fluoroscopy $(n=50)$ & 55 & 2.3 & 13 & 89 \\
Total $(n=101)$ & 56.9 & 1.6 & 13 & 9.25 \\
\hline
\end{tabular}

SD: standard deviation. 
Table 3. Comparison of outcome between the two groups

\begin{tabular}{|c|c|c|c|c|}
\hline & \multirow{2}{*}{ Outcome } & \multicolumn{2}{|c|}{ Groups } & \multirow{2}{*}{$P$ value } \\
\hline & & Blind $(n=51)$ & Fluoroscopy $(n=50)$ & \\
\hline \multirow{2}{*}{ Function-24 hour } & Optimal & $50(98.1)$ & $50(100)$ & \multirow{2}{*}{0.98} \\
\hline & Not-optimal & $1(1.9)$ & - & \\
\hline \multirow{2}{*}{ Function-1 month } & Optimal & $46(90.2)$ & $49(98)$ & \multirow{2}{*}{0.31} \\
\hline & Not-optimal & $5(9.8)$ & $1(2)$ & \\
\hline \multirow{2}{*}{ Exchange } & Yes & $2(3.9)$ & - & \multirow{2}{*}{0.31} \\
\hline & No & $49(96.1)$ & $50(100)$ & \\
\hline \multirow{2}{*}{ Complication } & Yes & $3(5.8)$ & - & \multirow{2}{*}{0.28} \\
\hline & No & $48(94.2)$ & $50(100)$ & \\
\hline
\end{tabular}

hemodialysis is an active and the treatment situations are altered at each session and appropriate dialysis would result in decreased side effects and better quality of treatment $(2,3)$. In cases needing urgent dialysis, the transient nontunneled catheters are good options for vascular access during hemodialysis $(18,19)$. For long-term cases, the grafts and fistulas are more optimal. During maturation of arteriovenous fistula or in hypotensive patients, permanent catheters are good options. The patient's situation may affect the used method. Transient methods are used in $7 \%$ which then are replaced with permanent methods $(20,21)$. The complications of vascular access are causes of admission in $16 \%$ to $25 \%$ of cases (22). Some complications can be fatal or with morbidity $(23,24)$

We matched the age and background disease between the groups to reduce the confounding effects. Our results for this matter were similar to other studies $(25,26)$. We found that function, side effects, and the need to exchange were similar between the two groups. The permanent catheter may be used if arteriovenous grafts and fistula are not appropriate. Previous studies have reported that early side effects are related to patient's age and the experience of surgeon. In this regard, age was matched in our study and the procedures were done by one surgeon.

\section{Conclusion}

We postulate that there is no significant difference between the placement of catheter by fluoroscope and blind method. Although the early function and side effects in our study were the same between the two groups, but we did not observe long term function and complications such as thrombosis that can be due to inappropriate position of catheter. In addition, although there is no statically difference between two methods in early complications but even one side effect such as vascular injury may be disaster and we recommend to insertion of permanent catheter under fluoroscopic guidance. However, further studies in this area with larger sample size are also recommended.

\section{Authors' contributions}

NM and SSV designed the concept. All authors collaborated in data acquisition. BG and SN analyzed and interpreted the data and drafted the manuscript. All authors critically reviewed the manuscript. All authors read and approved the final manuscript.

\section{Ethical Issues}

This clinical trial was approved by the ethics committee of Shahid Beheshti University of Medical Sciences (identifier: IRCT2016120329181N3). We declare the material is original writing, has not been previously published and has not been submitted for publication elsewhere while under consideration. All the individuals had been informed of the purposes of the study and gave their oral informed consent.

\section{References}

1. Pereira K, Osiason A, Salsamendi J. Vascular access for placement of tunneled dialysis catheters for hemodialysis: a systematic approach and clinical practice algorithm. J Clin Imaging Sci 2015; 5: 31. doi: 10.4103/2156-7514.157858.

2. Verrelli M. Chronic renal failure. Nephro Sci 2004; 231:2-8.

3. Tayyebi A, Babahaji M, Sadeghi Shermeh M, Ebadi A, Eynollahi B. Study of the effect of Hatha Yoga exercises on dialysis adequacy. Iran J Crit Care Nurse 2012; 4(4): 183-90.

4. Hassanzadeh J, Hashiani AA, Rajaeefard A, Salahi H, Khedmati E, Kakaei F, et al. Long-term survival of living donor renal transplants: A single center study. Indian J Nephrol 2010;20(4): 179-84. doi: 10.4103/0971-4065.73439.

5. Gallieni M, Brenna I, Brunini F, Mezzina N, Pasho S, Giordano A. Dialysis central venous catheter types and performance. J Vasc Access 2014; 15 Suppl 7: S140-6. doi: 10.5301/jva.5000262.

6. Scher LA, Shariff S. Strategies for hemodialysis access: a vascular surgeon's perspective. Tech Vasc Interv Radiol 2017; 20(1): 14-9. doi: 10.1053/j.tvir.2016.11.002.

7. Clark E, Kappel J, MacRae J, Dipchand C, Hiremath S, Kiaii $\mathrm{M}$, et al. Practical aspects of nontunneled and tunneled hemodialysis catheters. Can J Kidney Health Dis 2016; 3: 2054358116669128. doi: 10.1177/2054358116669128.

8. Mansfield PF, Hohn DC, Fornage BD, Gregurich MA, Ota DM. Complications and failures of subclavian-vein catheterization. N Engl J Med 1994; 331(26): 1735-8. doi: 10.1056/nejm199412293312602.

9. Souba WW, Fink MP, Jurkovic GJ, Kaiser LP, Pearce WH, Pemberton JH,et al. ACS Surgery: Principles and Practice. 6 ed. Decker Intellectual Properties Incorporated; 2007. 
10. Miller LM, MacRae JM, Kiaii M, Clark E, Dipchand C, Kappel J, et al. Hemodialysis tunneled catheter noninfectious complications. Can J Kidney Health Dis 2016; 3: 2054358116669130 . doi: 10.1177/2054358116669130.

11. Miller LM, Clark E, Dipchand C, Hiremath S, Kappel J, Kiaii $\mathrm{M}$, et al. Hemodialysis tunneled catheter-related infections. Can J Kidney Health Dis 2016; 3: 2054358116669129. doi: 10.1177/2054358116669129.

12. Milkowski A, Kirker A, Smolenski O, Hartwich A, Pietkun Z. Permanent catheter as an alternative vascular access for hemodialysis. Przegl Lek 1996; 53(11): 805-10. [In Polish].

13. Legendre C, Canaud B. Permanent catheters for hemodialysis: indications, methods and results. French national survey 1998-2000. Nephrologie 2001; 22(8): 385-9. [In French].

14. Dhingra RK, Young EW, Hulbert-Shearon TE, Leavey SF, Port FK. Type of vascular access and mortality in U.S. hemodialysis patients. Kidney Int 2001; 60(4): 1443-51. doi: 10.1046/j.1523-1755.2001.00947.x.

15. Lewis AL, Stabler KA, Welch JL. Perceived informational needs, problems, or concerns among patients with stage 4 chronic kidney disease. Nephrol Nurs J 2010; 37(2): 143-8; quiz 9.

16. Morton RL, Tong A, Howard K, Snelling P, Webster AC. The views of patients and carers in treatment decision making for chronic kidney disease: systematic review and thematic synthesis of qualitative studies. BMJ 2010; 340: c112. doi: 10.1136/bmj.c112.

17. Kiely R. Social work practice and NKF-DOQI: Social Work Intervention and Vascular access Guidelines; Fall 2003.

18. Kaplow R, Hardin SR. Critical care nursing: synergy for optimal outcomes. 1st ed. Jones \& Bartlett Learning; 2007.
19. Dix FP, Khan $\mathrm{Y}, \mathrm{Al}-\mathrm{Kh}$ affaf $\mathrm{H}$. The brachial arterybasilic vein arterio-venous fistula in vascular access for haemodialysis--a review paper. Eur J Vasc Endovasc Surg 2006; 31(1): 70-9. doi: 10.1016/j.ejvs.2005.08.008.

20. Safaie M, Moieni E, Goharian V. Efficacy of saphenofemoral $\mathrm{A}-\mathrm{V}$ fistula in cronic renal failure patients undergoing hemodialysis. J Shahid Sadoughi Univ Med Sci 2005; 13(1): 16-20.

21. Ghane Sherbaf F. Comparison of the complications of central vein catheters and arterio-venous fistulae in children on chronic hemodialysis. Iran J Pediatr 2006; 16(4): 407-12.

22. El Minshawy O, Abd El Aziz T, Abd El Ghani H. Evaluation of vascular access complications in acute and chronic hemodialysis. J Vasc Access 2004; 5(2): 76-82.

23. Shams Vahdati S. Should a double-lumen catheter be withdrawn? J Cardiovasc Thorac Res 2011; 3(3): 97-9. doi: 10.5681/jcvtr.2011.021.

24. Fadaei Haghi A, Shokri R, Shams Vahdati S, Eftekhar Milani F, Tajoddini S. A catheter malpositioned patient with pain and paresthesia. Journal of Emergency Practice and Trauma 2017; 3(1): 30-1. doi: 10.15171/jept.2017.11.

25. van Loon MM, Kessels AG, Van der Sande FM, Tordoir JH. Cannulation and vascular access-related complications in hemodialysis: factors determining successful cannulation. Hemodial Int 2009; 13(4): 498-504. doi: 10.1111/j.15424758.2009.00382.x.

26. Vascular Access 2006 Work Group. Clinical practice guidelines for vascular access. Am J Kidney Dis 2006; 48 Suppl 1: S248-73. doi: 10.1053/j.ajkd.2006.04.040. 